\title{
A man with intermittent fever and arthralgia
}

\author{
Susan M Knight, Deborah P M Symmons
}

\section{Case report}

A 44 year old, previously healthy, white man, who was a milk depot manager, was referred to a general physician in November 1991 with a 16 month history of febrile episodes, lasting for three or four days, which recurred approximately every six weeks. During the episodes his temperature rose to $40^{\circ} \mathrm{C}$, he felt flu-like and had aching limbs and profuse night sweats. $\mathrm{He}$ had no other symptoms of note and in particular no rash, no weight loss, no joint swelling, and no gastrointestinal or genitourinary symptoms. There was a family history of thyroid disease. He smoked 15-20 cigarettes a day. $\mathrm{He}$ had been on holiday to Tunisia in 1987, the Greek islands in 1990 and Portugal in 1991. $\mathrm{He}$ weighed $81.2 \mathrm{~kg}$. No abnormalities were found on examination. Initial investigations focused on screening for infection. Full blood count, erythrocyte sedimentation rate, renal function, liver function, thyroid function, chest radiography, and computed tomography of the abdomen were normal. Blood cultures were negative, as were a Mantoux test and early morning urine analysis for tuberculosis. $\mathrm{He}$ also had negative serology for syphilis, brucella, toxoplasma, and leptospirosis.

In May 1992 the febrile episodes became more frequent and he was referred for a second opinion to an infectious diseases unit. The differential diagnosis included an occult infection and a connective disease. An infection screen was again negative. Rheumatoid factor, antinucleur antibodies, and ds-DNA antibodies were negative and immunoglobulin concentrations were normal. It was suggested that he might have adult onset Still's disease. In November 1992 he was referred and admitted to a teaching hospital rheumatology unit for further investigation of his intermittent fevers and arthralgia. The arthralgia affected predominantly the left knee and shoulder. Examination was again normal with no rash, no lymphadenopathy and no synovitis. The differential diagnosis included occult infection, a malignancy (in particular a lymphoproliferative malignancy), inflammatory bowel disease, and a connective disease. Table 1 shows the indications and the results of his investigations.

The working diagnosis remained adult onset Still's disease and he was treated with indomethacin. In April 1993 he was given prednisolone $10 \mathrm{mg}$ daily because his joint symptoms were becoming more prominent, and he had some pleuritic chest pain although he still had no documented synovitis. Three months later his symptoms were no better and methotrexate was added. By September 1993 his fevers had largely settled but he began to complain of back pain. His modified Schober's index was $6 \mathrm{~cm}$.

By July 1994 he had begun to experience joint swelling as well as pain. $\mathrm{He}$ had documented synovitis of a number of small joints including the right wrist. There were no other new symptoms. He was taking prednisolone $5 \mathrm{mg}$ daily (which he increased to 15 mg when he experienced fevers) and methotrexate $12.5 \mathrm{mg}$ weekly. His erythrocyte sedimentation rate was $56 \mathrm{~mm} 1 \mathrm{st} \mathrm{h}$. In October 1994 he lost his job and subsequently became depressed, requiring treatment with dothiepin.

During 1995 he was referred to another rheumatologist in a nearby town for a further opinion but the diagnosis was not changed. He was then referred back to the original hospital for follow up in the newly established rheumatology department. He had synovitis of several
Department of

Rheumatology,

Macclesfield District

General Hospital,

Victoria Road,

Macclesfield, Cheshire

SK10 3BL

Correspondence to:

Dr Symmons.

Accepted for publication 15 September 1988
Table 1 Investigations performed in November 1992

\begin{tabular}{lll}
\hline Investigation & Indication & Result \\
\hline Cytomegalovirus antibody concentrations & To exclude current infection & Negative \\
Hepatitis B and C antibody concentrations & To exclude current infection & Negative \\
Coxiella burnetti antibody concentrations & To exclude current infection & Negative \\
Epstein-Barr virus antibody concentrations & To exclude current infection & Evidence of past infection \\
Bone marrow culture & To exclude tuberculosis & Negative \\
Labelled white cell scan & To exclude current infection & Negative \\
Abdominal ultrasound & To look for evidence of tumour, lymphadenopathy, & Normal \\
& abscess, interstitial liver disease & \\
Liver biopsy & To look for evidence of inflammatory or malignant & Normal \\
Echocardiogram & disease & \\
Barium follow through & To look for evidence of endocarditis & Normal \\
To look for evidence of inflammatory bowel & Normal \\
cANCA & disease or lymphoma & Low titre 1/30 \\
Sinus radiographs & To look for evidence of vasculitis especially & Wegener's granulomatosus \\
& To look for evidence of Wegener's granulomatosus & Bilateral mucosal thickening
\end{tabular}




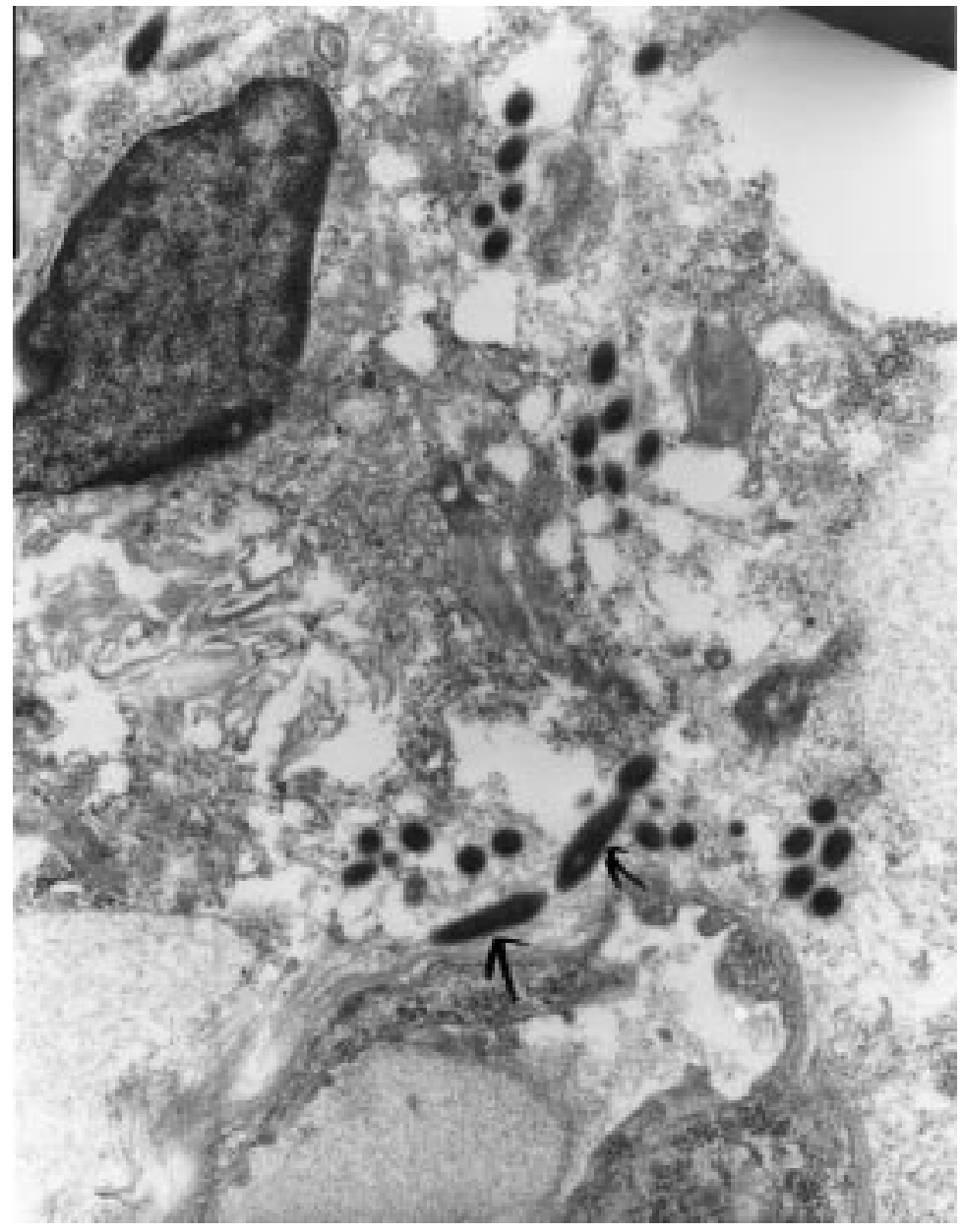

Figure 1 Electron micrograph of a duodenal biopsy of the patient showing bacterial rods characteristic of Whipple's disease.

peripheral joints. At this point he remained rheumatoid factor negative, had no radiological erosions or sacroiliitis. He was HLA-B27 negative. The differential diagnosis included undifferentiated seronegative spondarthritis and adult onset Still's disease. Follow up was continued.

In January 1997 his weight was $82.6 \mathrm{~kg}$. In April 1997 he had an abrupt onset of watery diarrhoea with a stool frequency of up to 10 times per 24 hours. This was associated with gripping lower abdominal pain especially after meals. There was no blood or mucus in the stools. His weight fell rapidly to $73.0 \mathrm{~kg}$ within four weeks of onset. Differential diagnosis included intestinal infection, inflammatory bowel disease, and malignant disease. Stool cultures were negative. Barium enema was normal and flexible sigmoidoscopy showed only diffuse mild erythema. Barium follow through showed appearances consistent with malabsorption with a slow rate of passage through the small bowel, some dilatation of the small bowel, straightening of the valvulae conniventes, and moulage. A duodenal biopsy was performed to look for the organisms of Whipple's disease. It showed large macrophages in the lamina propria, the cytoplasm of which contained large amounts of diastase resistant PAS positive material. Bacterial rods characteristic of Whipple's disease were seen on electron microscopy (fig 1). Because Whipple's disease can affect the central nervous system, baseline magnetic resonance imaging of the brain was performed. It was normal. By the time the diagnosis of Whipple's disease was confirmed in early July 1997 his weight had fallen to $62.6 \mathrm{~kg}$. His methotrexate was stopped and he was given high dose co-trimoxazole. Within three days his diarrhoea had stopped. By December 1997 his weight had returned to $78.7 \mathrm{~kg}$ and he had no peripheral synovitis. His depression had resolved. He did however have increasing lower back pain and his Schober had fallen to $4.7 \mathrm{~cm}$. His sacroiliac radiographs were normal.

\section{Discussion}

From the rheumatological perspective, it is easy to think of and diagnose Whipple's disease once a patient with a migratory seronegative arthritis develops severe diarrhoea and weight loss. The main question raised by this case is whether the diagnosis should have been considered, or could have been made, sooner. Recent advances in the understanding of the aetiology of Whipple's disease make it timely to review this issue.

\section{DIFFERENTIAL DIAGNOSIS}

George Whipple first described this condition in $1907 .{ }^{1}$ His patient was a 36 year old male physician who developed an intermittent, migratory polyarthritis while working as a medical missionary in Constantinople. One year later he developed a chronic cough. Seven years after the onset he began to have evening fevers and then developed diarrhoea and weight loss. He died five months after this.

The condition is rare. In 1985 Dobbins estimated that there had been 2000 cases since the original description in $1907 .^{2}$ The great majority have been middle aged white men from the US and Europe. The disease seems to be more common in farmers and people in farm related trades. ${ }^{3}$ Our patient worked in a milk depot. The causal organism has recently been identified as a Gram positive actinomycete, which has been named Tropheryma whippelii from the Greek trophi (nourishment) and eryma (barrier) because of the malabsorption syndrome it causes. ${ }^{4}$ The actinomycetes are a diverse group of bacteria most of which are aerobic soil organisms-which may account for the link with farming.

The clinical manifestations of Whipple's disease are many and diverse. Almost all organ systems can be involved. Table 2 lists the more commonly reported features. In approximately two thirds of patients, the disease begins insidiously with either arthralgia or a migratory, non-erosive, non-deforming seronegative arthritis. This may precede any other features by up to 24 years. $^{56}$ Clearly the differential diagnosis depends on what other clinical features are present. In our patient, fever was the most prominent symptom apart from arthralgia. This led an infectious disease consultant, a professor of medicine, and two rheumatologists to the conclusion that, once 
Table 2 Clinical features of Whipple's disease

\begin{tabular}{|c|c|c|}
\hline & Symptoms & Signs \\
\hline \multirow[t]{7}{*}{ Gastrointestinal } & Weight loss` & Occult blood loss \\
\hline & Diarrhoea ${ }^{\star}$ & Abdominal distension ${ }^{\star}$ \\
\hline & Anorexia ${ }^{\star}$ & Cachexia \\
\hline & Abdominal pain & Ascites \\
\hline & Melaena & Hepatomegaly \\
\hline & & Splenomegaly \\
\hline & & Glossitis \\
\hline \multirow[t]{2}{*}{ Musculoskeletal } & Arthralgia $^{\star}$ & Arthritis` \\
\hline & Myalgia & Sacroiliitis \\
\hline \multirow[t]{2}{*}{ Respiratory } & Chronic cough & Pleural rub \\
\hline & Pleuritic pain & \\
\hline \multirow[t]{3}{*}{ Cardiovascular } & Pericardial pain & Congestive cardiac failure \\
\hline & & Heart murmurs \\
\hline & & Hypotension \\
\hline \multirow[t]{7}{*}{ Neurological/psychiatric } & Insomnia & Dementia \\
\hline & Headache & Peripheral neuropathy \\
\hline & Depression & Ataxia \\
\hline & Fits & Ophthalmoplegia \\
\hline & Visual disturbance & Nystagmus \\
\hline & Memory loss & Myoclonus \\
\hline & Personality change & Hypothalamic dysfunction \\
\hline \multirow[t]{4}{*}{ Other } & Fever ${ }^{\star}$ & $\begin{array}{l}\text { Peripheral and abdominal } \\
\text { lymphadenopathy }\end{array}$ \\
\hline & Fatigue $\star$ & Anaemia \\
\hline & & Hyperpigmentation \\
\hline & Night sweats & Uveitis \\
\hline
\end{tabular}

ॠCommon (more than $50 \%$ of cases in most series).

infection had been excluded, adult onset Still's disease was the most likely diagnosis. But, of course, infection had not been excluded!

The differential diagnosis between adult onset Still's disease and Whipple's disease has not received much attention in the medical literature. This is rather surprising as the fever of Whipple's disease occurs most commonly in patients who also have arthritis. ${ }^{6}$ Table 3 shows a comparison of the epidemiological and clinical features of the two diseases. If a patient has fever and arthritis (but no diarrhoea) then the most important distinguishing features are the presence of a characteristic salmon-pink evanescent rash in most patients with adult onset Still's disease as well as a marked neutrophilia.

There are no widely accepted diagnostic or classification criteria for adult onset Still's disease. Some authors have used the EULAR or ACR criteria for systemic onset juvenile arthritis (which require an arthritis to be present for

Table 3 Comparison between Whipple's disease and adult onset Still's disease

\begin{tabular}{|c|c|c|}
\hline & $\begin{array}{l}\text { Whipple's disease } \\
\text { (adapted } \text { from }^{67} \text { ) }\end{array}$ & $\begin{array}{l}\text { Adult Still's disease } \\
\text { (adapted from }^{8} \text { ) }\end{array}$ \\
\hline Occurrence & Rare & Uncommon \\
\hline Male:female & $8: 1$ & $1: 1$ \\
\hline Peak age at onset & $30-60$ & $16-35$ \\
\hline Mean age at onset & 49 & 30 \\
\hline Ethnicity & Predominantly white & Worldwide \\
\hline \multicolumn{3}{|l|}{ Clinical features } \\
\hline \multicolumn{3}{|l|}{ Fever } \\
\hline Frequency & $10-55 \%$ & $96 \%$ \\
\hline Type & $\begin{array}{l}\text { Usually low grade, } \\
\text { intermittent }\end{array}$ & Usually high spiking once or twice a day \\
\hline \multicolumn{3}{|c|}{ 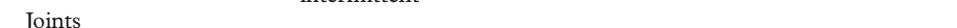 } \\
\hline Arthralgia & $>80 \%$ & $100 \%$ \\
\hline \multirow[t]{3}{*}{ Arthritis } & Often transient & $\begin{array}{l}\text { Usually persisent or in episodes of }>2 \\
\text { weeks }\end{array}$ \\
\hline & Large $>$ small joints & Large $>$ small joints \\
\hline & Usually non-deforming & Deforming in $31 \%$ \\
\hline Radiology & Usually non-erosive & Often erosive and ankylosing eventually ${ }^{9}$ \\
\hline \multicolumn{3}{|l|}{ Others } \\
\hline Weight loss $\geqslant 10 \%$ & $95 \%$ & $38 \%$ \\
\hline Lymphadenopathy & $50 \%$ & $60 \%$ \\
\hline Hepatosplenomegaly & $15 \%$ & $48 \%$ \\
\hline Rash & - & $88 \%$ \\
\hline Diarrhoea & $75 \%$ & - \\
\hline Adominal pain & $60 \%$ & $13 \%$ \\
\hline Neutrophilia (15 000) & - & $75 \%$ \\
\hline
\end{tabular}

Table 4 Diagnostic criteria for adult Still's disease. (Proposed by Cush et al ${ }^{t}$ )

\begin{tabular}{cl}
\hline All of & \\
\hline 1 & Fever $\geqslant 39^{\circ} \mathrm{C} \dagger$ \\
2 & Arthralgia or arthritis \\
3 & Rheumatoid factor $<1: 80^{\star}$ \\
4 & Antinuclear antibody titre $<1: 100^{\star}$ \\
Plus any two of \\
1 & White cell count $\geqslant 15000 / \mathrm{mm}^{3}$ \\
2 & Typical Still's rash \\
3 & Serositis (pleuritis or pericarditis) $\dagger$ \\
4 & Reticuloendothelial involvement $\dagger$ \\
& generalised lymphadenopathy, \\
& hepatomegaly or splenomegaly) \\
\hline
\end{tabular}

$\star$ Present in $>50 \%$ of patients with Whipple's disease. $†$ Present in $30-50 \%$ of patients with Whipple's disease.

three months or six weeks respectively, plus daily intermittent temperature increases to $39.5^{\circ} \mathrm{C}$ or more). Our patient would have satisfied these criteria by July 1994 when he first had documented synovitis. An alternative set of criteria was proposed by Cush et $a l^{10}$ (table 4) and these are likely to be more specific. Although our patient satisfied the four mandatory criteria, he only had one of the additional criteria (serositis). However, both serositis and reticuloendothelial involvement occur in Whipple's disease and so a patient with Whipple's could satisfy the Cush criteria.

EARLIER DIAGNOSIS

By the time this patient was diagnosed as having Whipple's disease he had been unwell for six years, attended four different hospitals, and had a multitude of investigations. He had first changed and then lost his job. He had been taking corticosteroids and methotrexate for four years. Even if the diagnosis had been considered before the onset of his diarrhoea, could it have been established?

Black-Schaffer first described in 1949 the characteristic histological changes on which the diagnosis of Whipple's disease has since been based. ${ }^{11} \mathrm{He}$ found that foamy macrophages in the lamina propria of the intestinal mucosa of affected patients contained large amounts of PAS positive, diastase resistant material. Electron microscopy of affected tissue shows characteristic rod shaped bacilli that are both intracellular and extracellular ${ }^{12}$ (fig 1). PAS positive macrophages and the characteristic bacilli have also been found in non-intestinal tissues including liver, lung, heart, brain, lymph node, and synovium. ${ }^{13}$ Intestinal infection with Mycobacterium avium or Mycobacterium intracellulare (such as occurs in patients with AIDS) also gives infiltration of the lamina propria with PAS positive macrophages but the latter bacilli are acid fast whereas the Whipple's organism is not. Intestinal biopsy may be positive in Whipple's disease before the onset of diarrhoea but this is not always the case. ${ }^{14}$

The possibility of making an early diagnosis of Whipple's disease has been increased with the recent advent of polymerase chain reaction (PCR) based techniques. These genetic techniques permit the identification of a species specific 16s ribosomal RNA gene of Tropheryma whippelii in affected tissues. ${ }^{4}$ The PCR 
tests could demonstrate $T$ whippelii in tissues that showed no evidence of disease histologically. Ramzan et al looked at 30 patients with histologically confirmed Whipple's disease and eight in whom the disease was suspected but could not be confirmed. ${ }^{15}$ Results from tissues were positive in 29 of 30 patients with confirmed Whipple's disease and seven of eight of those suspected to have the disease. On biopsies taken after treatment, results from PCR were found to be better than conventional histology at predicting relapse.

$T$ whippelii has also been identified in peripheral blood and pleural effusion cells. ${ }^{16}$ Clearly it would be a major advance if Whipple's disease could be diagnosed by PCR techniques on peripheral blood mononuclear cells, before the onset of intestinal symptoms. Unfortunately, this does not seem to be a sufficiently sensitive test. Müller et al obtained positive results from peripheral blood on two out of four confirmed cases of Whipple's disease. ${ }^{17}$ They concluded that the blood test could not be used as a substitute for biopsy.

TREATMENT

The final aspect to consider in this case is the treatment. Before the introduction of antibiotic regimens in 1952, diagnosed Whipple's disease was universally fatal. A variety of antibiotic regimens are suggested and none is universally successful. Patients often relapse, even after prolonged courses of antibiotics, and the relapses often involve the central nervous system and may be progressive. It was with this in mind, that baseline magnetic resonance imaging of the brain was performed in this patient. There is evidence that co-trimoxazole penetrates the blood brain barrier better than other antibiotics and so reduces the risk of CNS relapses. ${ }^{18}$ In the majority of patients the diarrhoea ceases within 2-7 days of starting antibiotics and the joint pain within a month.
Treatment has to be continued for at least a year. The disease is too rare to conduct randomised controlled clinical trials.

1 Whipple GH. A hitherto undescribed disease characterised anatomically by deposits of fat and fatty acids in the intestinal and mesenteric lymphatic tissues. Bull Johns Hopkins Hosp 1907;18:382-91.

2 Dobbins WO III. Whipple's disease: A historical perspective. Q J Med 1985;56:523-31.

3 Dobbins WO III. Whipple's disease. Springfield, IL: Charles C Thomas, 1987 .

4 Relman DA, Schmidt TM, MacDermott RP, Falkow S. Identification of the uncultured bacillus of Whipple's disease. N Engl J Med 1992;372:293-301.

5 Schilling D, Adamek HE, Kaufmann V, Maier M, Riemann JF. Arthralgia as an early extraintestinal symptom of Whipple's disease. J Clin Gastroenterol 1997;24:18-20.

6 Corner GM, Brandt LJ, Abissi CJ. Whipple's disease: A review. Am J Gastroenterol 1983;78:107-14.

7 Maizel H, Ruffin JM, Dobbins WO. Whipple's disease: A review of 19 patients from one hospital and a review of the literature since 1950. Medicine (Baltimore) 1970;49:175205.

8 Onta A, Yamaguchi M, Kaneoka H, Nagayoshi T, Hiida M. Adult Still's disease:review of 228 cases from the literature. Adult Still's disease:review of 228 .

9 Pouchot J, Sampalis JS, Beaudet F, Carette S, Décary F, Salusinsky-Sternbach M, et al. Adult Still's disease: manifestations, disease course and outcome on 62 patients. Medicine (Baltimore) 1991;70:118-36.

10 Cush JJ, Medsger TA, Christy WC, Herbert DC, Cooperstein LA. Adult onset Still's disease:clinical course and outcome. Arthritis Rheum 1987;30:186-94.

11 Black-Schaffer B. The tinctoral demonstration of a glycoprotein in Whipple's disease. Proc Soc Exp Biol Med 1949; protein in $225-7$.

12 Chears WC, Ashworth CT. Electron microscopic study of the intestinal mucosa in Whipple's disease: demonstration of encapsulated bacilliform bodies in the lesion. Gastroenterology 1961;41:129-38.

13 Marth T, Strober W. Whipple's disease. Semin Gastrointest Dis $1996 ; 7: 41-8$.

14 Feurle GE, Volk B, Waldkerr R. Cerebral Whipple's disease with negative jejunal histology. N Engl J Med 1979;300: 907-8.

15 Ramzan NN, Loftus E, Burgart LJ, Rooney M, Batts KP, Wiesner $\mathrm{RH}$, et al. Diagnosis and monitoring of Whipple disease by polymerase chain reaction. Ann Intern Med 1997;126:520-7.

16 Müller C, Stain C, Burghuber O. Tropheryma whippelii in peripheral blood mononuclear cells and cells of pleural

17 Müller C, Petermann D, Stain C, Riemer H, Vogelsang H, Schnider P. Whipple's disease: comparison of histology with diagnosis based on polymerase chain reaction in four consecutive cases. Gut 1997;40:425-7.

18 Feurle GE, Marth T. An evaluation of antimicrobial treatment for Whipple's disease: tetracycline versus trimethoprim - cotrimoxazole. Dig Dis Sci 1994;39:1642-8. 